\title{
In situ study of erosion and deposition of amorphous hydrogenated carbon films by exposure to a hydrogen atom beam
}

\author{
Sabina Markelj ${ }^{\mathrm{a})}$, Primož Pelicon, Iztok Čadež \\ Jožef Stefan Institute and Association EURATOM-MHEST, Jamova cesta 39, SI-1000 Ljubljana, Slovenia \\ Thomas Schwarz-Selinger, Wolfgang Jacob \\ Max-Planck-Institut für Plasmaphysik (IPP), EURATOM Association, Boltzmannstr. 2, D-85748 Garching, Germany
}

(published 5 June 2012 in J. Vac. Sci. Technol. A 30(4), Jul/Aug 2012)

\begin{abstract}
Here we report on the first dual-beam experiment employing a hydrogen atom beam for sample exposure and an ion beam for analysis, enabling in situ and real time studies of hydrogen atom interaction with materials. The erosion of an amorphous hydrogenated carbon (a-C:H) layer by deuterium atoms at $580 \mathrm{~K}$ sample temperature was studied and the uptake of deuterium during the erosion process was measured in real time. The deuterium areal density increased at the beginning to $7.3 \times 10^{15}$ at. $\mathrm{cm}^{-2}$, but then stabilized at a constant value of $5.5 \times 10^{15}$ at. $\mathrm{cm}^{-2}$. Formation of a polymerlike deposit on an a-C:H layer held at room temperature and subjected to the deuterium atom beam was observed and also studied in-situ. For both erosion and deposition studies an a- ${ }^{13} \mathrm{C}: \mathrm{H}$ layer on top of a Si substrate was used as a sample, making the experiments isotopically fully specified and thereby differentiating the deposited from the original layer and the interacting $\mathrm{D}$ atoms from $\mathrm{H}$ atoms present in the layer and in the residual vacuum. From the deposition study it was shown that carbon in the deposited layer originates from carbon-carrying species in the background vacuum that interact with hydrogen atoms. The areal density of the carbon at the surface was determined from the energy shift of the Si edge in the RBS spectrum. The cross-section for ${ }^{7} \mathrm{Li}$ on $\mathrm{D}$ at $4.3 \mathrm{MeV} \mathrm{Li}$ ion energy and at a recoil angle of $30^{\circ}$ was also determined to be $(236 \pm 16) \times 10^{-27} \mathrm{~cm}^{2} / \mathrm{sr}$. This is a factor of $3 \pm 0.2$ times higher than the Rutherford elastic cross-section.
\end{abstract}

a) electronic mail: sabina.markelj@ijs.si 


\section{INTRODUCTION}

Studies of atomic hydrogen interaction with materials represent an extensive and important research activity due to the fundamental nature of corresponding processes, e.g. atom recombination on surfaces and interaction in the interstellar medium, and due to the technological importance of the interaction of hydrogen plasmas with carbon or polymer surfaces such as in processing plasmas and in the edge plasma in experiments for magnetically confined thermonuclear fusion. Here we study the interaction of hydrogen atoms with amorphous hydrogenated carbon $(\mathrm{a}-\mathrm{C}: \mathrm{H})$ films. Hydrogen interaction plays an important role in erosion and deposition of such layers and understanding the processes that take place during erosion and re-deposition of carbon layers is important, especially in present day fusion experiments with carbon walls and in the future fusion reactor ITER where carbon fiber composites are foreseen for use in the divertor strike zones. ${ }^{1}$ Namely, re-deposition of carbon is a critical process regarding the limitation of the permissible amount of retained tritium ${ }^{1}$ since carbon re-deposition is accompanied by the co-deposition of hydrogen isotopes. Plasma-deposited $\mathrm{a}-\mathrm{C}: \mathrm{H}$ films are a model system for such re-deposited carbon films.

The formation of amorphous hydrogenated carbon films in polymer-like or diamond-like form is also extensively studied due to scientific and technological interest in such films ${ }^{2}$ which stems from the variety of technologically attractive film properties which can be achieved by controlling the deposition conditions. This is especially the case for the synthesis of diamond-like carbon films due to properties such as high chemical resistance, mechanical hardness and transparency in IR, which are useful in a wide range of applications. ${ }^{3}$ There are many possible ways for depositing such layers, e.g. hot filament chemical vapor deposition (HF-CVD) or plasma chemical vapor deposition (PCVD) and it has been shown that hydrogen atoms play an important role in the CVD process. $^{4,5}$

A detailed insight into the film formation and etching was obtained by particle-beam experiments where the influence of hydrogen atoms was studied extensively., ${ }^{2,4,6,7} \mathrm{On}$ the one hand, if an a-C:H layer at elevated temperatures is exposed to hydrogen atoms the atoms erode the layer with an erosion yield that is temperature and flux dependent and reaches a maximum at $650 \mathrm{~K}$ for a flux of $10^{16} \mathrm{~cm}^{-2} \mathrm{~s}^{-1}{ }^{8}$ This erosion process by hydrogen atoms is the basis of a method for quantifying the atom flux density profile to the sample surface whereby the change of the layer thickness due to erosion can be used to directly obtain the atom flux density on the sample. ${ }^{9}$ The incident hydrogen atoms are also important for film growth because they influence the layer properties and its growth rates ${ }^{5}$ by abstraction of surface-bonded hydrogen which continuously creates reactive sites (dangling bonds) onto which neutral hydrocarbon radicals are preferably adsorbed. On the other hand, the hydrogen atoms can also attach to these dangling bonds and, by doing so, prevent the reconstruction to non-diamond forms during diamond-like film growth and convert carbon sites with $\mathrm{sp}$ and $\mathrm{sp}^{2}$ character into $\mathrm{sp}^{3}$ character. ${ }^{5,10,11}$

A dual-beam arrangement was used for the present study with a thermal hydrogen atom beam being employed for sample exposure and a $\mathrm{MeV}$ ion beam for sample composition analysis. The ion beam analytical methods ERDA (Elastic Recoil Detection Analysis) and RBS (Rutherford Back Scattering) were used. Here we report on the time evolution of the erosion of hard a-C:H layers during exposure to a $\mathrm{D}$ atom beam. Additionally the deposition of a polymer-like (soft) $\mathrm{C}: \mathrm{H}$ film on top of the a-C:H film was observed during sample exposure to a hydrogen atom beam with the sample held at room temperature. This deposition was also studied in-situ during exposure to D atoms by ERDA and RBS methods. The experiment was isotopically fully specified. This allowed differentiation of the deposited carbon $\left({ }^{12} \mathrm{C}\right)$ from the carbon initially present in the sample $\left({ }^{13} \mathrm{C}\right)$ layer as well as differentiation of the $\mathrm{D}$ atoms incorporated in the film from the incident beam and the $\mathrm{H}$ atoms that were either originally present in the initial sample layer or were incorporated together with carbon carrying impurity molecules from the background vacuum.

\section{EXPERIMENT}

In order to obtain a deeper insight into the processes occurring during the material exposure to hydrogen atoms, hydrogen $^{12}$ and the sample material densities were measured in-situ by ion beam methods. For this purpose the ERDA and RBS methods were applied using the 2 MV tandem accelerator (HV Tandetron) at the Jožef Stefan Institute (JSI), Ljubljana. Measurements were performed using a $4.3 \mathrm{MeV}$ ${ }^{7} \mathrm{Li}^{2+}$ beam and, in some RBS measurements, a $1.56 \mathrm{MeV}$ proton beam was used for carbon evaluation employing proton enhanced-cross-section scattering (PES). ${ }^{13}$ The experimental configuration used for the present measurements is shown schematically in Fig. 1.

The ion beam was collimated to $2 \times 1 \mathrm{~mm}^{2}$ with a vertical rectangular shaping slit placed in front of the experimental chamber entrance and a mesh charge collector mounted behind the shaping slit was used for absolute dose calibration. ${ }^{14}$ A conventional silicon detector used for detecting recoiled particles (ERDA detector) was placed at an angle $\varphi=30^{\circ}$ with respect to the incoming beam and a $12.5 \mu \mathrm{m}$ thick 
kapton foil was placed in front of the ERDA detector in order to stop the scattered Li particles. Another detector placed at an angle $\vartheta=165^{\circ}$ with respect to the incoming beam (RBS detector), was used for detecting the backscattered $\mathrm{Li}$ ions and, with this detector, the concentration depth profiles of species heavier than Li can be measured. The energy scale of the RBS detector was calibrated by multi-target elemental analysis and was determined to be $8.7 \mathrm{keV} /$ channels for a $4.3 \mathrm{MeV}{ }^{7} \mathrm{Li}^{2+}$ beam. A thin aluminium foil $(0.8 \mu \mathrm{m})$ was placed in front of both detectors in order to prevent radiation from the hydrogen atom beam source creating noise in these detectors. The ion beam was probing the target at an $\alpha=15^{\circ}$ glancing angle with respect to the sample surface. The ion beam, sample normal and both detection axes (ERDA and RBS) are in one plane.

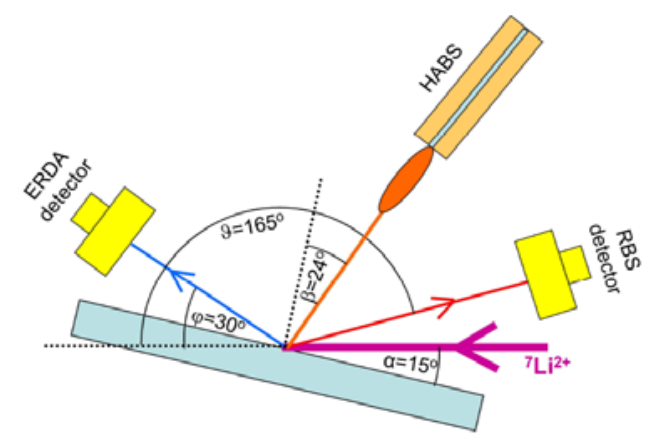

Figure 1. The dual beam experimental configuration for the in situ studies of hydrogen atom interaction with materials by ion beam methods ERDA and RBS. The hydrogen atom beam is produced by a hot capillary source (HABS).

The $\mathrm{H}$ and $\mathrm{D}$ concentration depth profiles can be determined by analysing the energy spectrum of the recoiled particles since recoiled $\mathrm{H}$ and $\mathrm{D}$ from the same depth are well separated in energy due to the mass dependence of the recoil kinematic factor. The SIMNRA program ${ }^{15}$ was employed to determine the surface areal densities of $\mathrm{H}$ and $\mathrm{D}$ from the measured spectra. Accurate elastic recoil cross-sections (CSs) are needed for the quantitative application of ERDA and the $\mathrm{CS}$ for ${ }^{7} \mathrm{Li}$ on $\mathrm{H}$ strongly deviates from the Rutherford crosssection $^{16}$ so accurate experimental $\mathrm{CSs}^{17}$ were used for the present spectra evaluation. For the case of ${ }^{7} \mathrm{Li}$ on $\mathrm{D}$, accurate CSs are not available in the literature and, therefore, to determine the needed cross-section the following procedure was applied: First, a hard a-C:D film was grown on a Si (001) wafer at the Max Planck Institut für Plasmaphysik (IPP), Garching, by plasma deposition applying an asymmetrical, capacitively coupled discharge $(13.56 \mathrm{MHz})$ using pure $\mathrm{CD}_{4}$ (D enrichment 99.5\%). The samples were characterized independently by NRA (Nuclear Reaction Analysis) at the tan- detron accelerator laboratory at IPP, Garching, applying the $\mathrm{D}\left({ }^{3} \mathrm{He}, \mathrm{p}\right)^{4} \mathrm{He}$ nuclear reaction at $690 \mathrm{keV}$ primary energy. With the cross-section taken from Ref. 18, the deuterium areal density in the film obtained from the measurement at IPP was $3.1 \times 10^{17} \mathrm{D} / \mathrm{cm}^{2}$ and the areal carbon density was determined by PES with $1.5 \mathrm{MeV}$ protons and found to be $4.4 \times 10^{17} \mathrm{C} / \mathrm{cm}^{2}$. The ERDA spectra with a $\mathrm{Li}$ ion beam were then measured at JSI on a-C:D films from the same wafer with the deuterium areal density measured at IPP taken as a fixed parameter in ERDA simulation of the JSI measurement. With these measurements a cross-section for the $4.3 \mathrm{MeV}$ ${ }^{7} \mathrm{Li}^{+2}$ beam energy on $\mathrm{D}$ was obtained and found to be $(236 \pm 16) \times 10^{-27} \mathrm{~cm}^{2} / \mathrm{sr}$. This value is $3.0 \pm 0.2$ times higher than the Rutherford elastic cross-section $\left(79 \times 10^{-27} \mathrm{~cm}^{2} / \mathrm{sr}\right)$ at the same projectile energy and recoil angle of $\varphi=30^{\circ}$. The same samples were also analysed by a new micro-NRA detection set-up at $\mathrm{JSI}^{19}$ and the agreement with the IPP NRA measurements is within the estimated experimental uncertainty. The resulting cross-section is valid only for the D surface peak; namely, the ERDA spectrum was measured at one ion-beam energy and the a-C:D film was thin enough $(60 \mathrm{~nm})$ so that the detected $\mathrm{D}$ peak can be considered as originating from a surface layer. To the authors' knowledge this cross-section has not been measured before and is of crucial importance for our evaluation of the D surface areal density.

In the course of the experiment we used wellcharacterized samples with an a- ${ }^{12} \mathrm{C}: \mathrm{H}$ or a- ${ }^{13} \mathrm{C}: \mathrm{H}$ layer on a silicon substrate, which were plasma-deposited on a $\mathrm{Si}(001)$ wafer with methane isotopologue ${ }^{13} \mathrm{CH}_{4}$ or ${ }^{12} \mathrm{CH}_{4}$ as the working gas. Samples were prepared and also characterised by ellipsometry ${ }^{2}$ at IPP, Garching. Three kinds of samples were used in the present study: one with an approximately $70 \mathrm{~nm}$ thick a- ${ }^{12} \mathrm{C}: \mathrm{H}$ layer and two with a- ${ }^{13} \mathrm{C}: \mathrm{H}$ layers, one set with $20 \mathrm{~nm}$ and another set with $64 \mathrm{~nm}$ thickness. The size of the samples was $30 \times 40 \mathrm{~cm}^{2}$. Samples were mounted by two metal clamps on a special holder in the ERDA/RBS vacuum chamber which holder enables variation of the sample temperature from 285 to $670 \mathrm{~K}$, as measured by two thermocouples touching the sample's top surface.

A hydrogen atom beam source (HABS) from MBEKomponenten $\mathrm{GmbH}^{20}$ was used in the present study and was mounted in the chamber so that the axis of the beam of hydrogen atoms ( $\mathrm{H}$ or $\mathrm{D}$ ) was directed to the sample at an angle of $\beta=24^{\circ}$ with respect to the sample's normal (Fig. 1). The hydrogen atom beam is created by dissociation of hydrogen molecules flowing through the hot tungsten capillary. During the experiment the capillary was always heated by the same heating power of $175 \mathrm{~W}$, providing a capillary temperature of $2200 \mathrm{~K}$. The distance between the capillary exit and the sample was $7.9 \mathrm{~cm}$ and the mean kinetic energy of atoms hitting 
the sample surface was $0.19 \mathrm{eV}$, assuming that it is determined by the temperature of the capillary.

We performed several exposure experiments with the a-C:H samples and all exposure conditions were similar in these experiments except for the sample temperature and the fuelling gas $\left(\mathrm{H}_{2}\right.$ or $\left.\mathrm{D}_{2}\right)$, which were varied. Exposure experiments were performed at two temperatures, $\approx 550 \mathrm{~K}$ and $\approx 295 \mathrm{~K}$. The average driving pressure measured in the supply side of the tungsten capillary, used for molecule cracking in the HABS, was approximately $0.17 \mathrm{mbar}$ in the case of $\mathrm{H}_{2}$ operation and 0.19 mbar in the case of $\mathrm{D}_{2}$ operation. In order to study the processes occurring on the a-C:H layer at high and low temperatures two different samples with $a-{ }^{13} \mathrm{C}: \mathrm{H}$ layers were exposed to the D beam and, simultaneously during the exposure, ERDA and RBS were used to analyze the layer. After the exposure the samples were analyzed with ellipsometry to determine the lateral distribution of the thickness of the final layer.

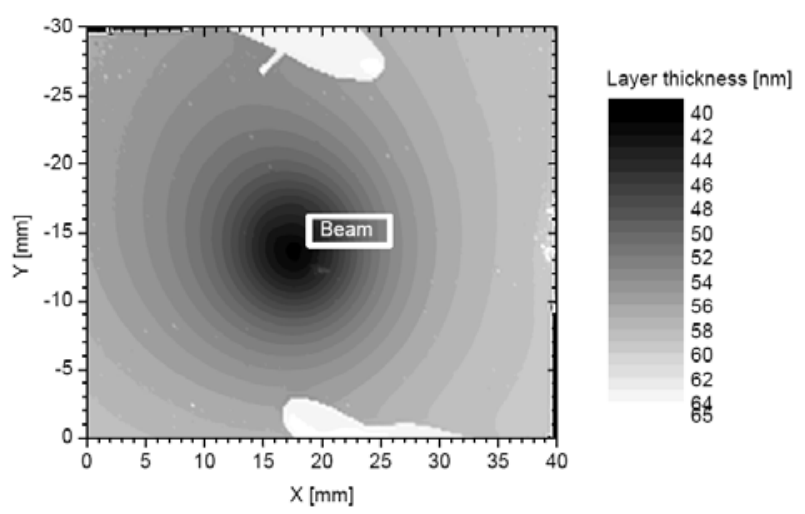

Figure 2. Lateral thickness distribution of the eroded layer measured ex-situ by ellipsometry. The thinner the layer, the higher was the local atomic flux density during the exposure. Part of the sample was masked by holding clamps providing the original thickness of the layer as a reference. A thin shadow of the thermocouple is visible adjacent to the upper clamp. The area where the ion probing beam hit the sample is marked as "Beam".

Before the in situ studies, high-temperature exposures were performed to determine the $\mathrm{H}$ and $\mathrm{D}$ atom flux density to the sample, as outlined in Ref. 9. The lateral distribution of the thickness of the a- ${ }^{13} \mathrm{C}: \mathrm{H}$ layer was also analyzed by ellipsometry ex-situ after the exposure experiment. The obtained layer-thickness profile over the whole sample is shown in Fig. 2 for the case of D atom flux. A part of the sample surface was covered by holding clamps and in these regions the film still has its original thickness and, therefore, these regions can be used as a thickness reference. The D density flux is then calculated as $j=\Delta d n_{C} / Y t$ (Ref. 9), where $\Delta d$ is the difference between the initial and the final layer thickness, $n_{C}$ is the carbon density $\left(9 \times 10^{22} \mathrm{C}\right.$ at. $/ \mathrm{cm}^{3}$, Ref. 9), $Y$ is the erosion yield $(Y=0.0153 \text { at } 580 \mathrm{~K})^{8}$ and $t$ is the exposure time $(12900 \mathrm{~s})$. The central atom flux density, calculated by the above equation from the a-C:H layer thickness analysis by ellipsometry, was determined to be $(1.0 \pm 0.05) \times 10^{15}$ at. $\mathrm{cm}^{-2} \mathrm{~s}^{-1}$. The D flux density at the ion beam position needs to be averaged over the size of the probing ion beam $\left(2 \times 5 \mathrm{~mm}^{2}\right.$ on the sample), taking also into account the exact position of the two beams. The size as well as the position of the probing beam, marked in Fig. 2, was visualized on the kapton foil and on a soft a-C:H layer for exposure at RT, see Fig. 8. The eroded layer thickness as measured by ellipsometry was averaged over the ion beam position and from this the average D flux density was calculated to be approximately $(8.4 \pm 0.5) \times 10^{14}$ at. $^{-2} \mathrm{~s}^{-1}$. A typical $\mathrm{H}$ central atom flux density at the sample, as obtained by analysing the eroded a-C:H layer after exposure to the $\mathrm{H}$ atom beam at an elevated temperature, was $1.6 \times 10^{15}$ at. $\mathrm{cm}^{-2} \mathrm{~s}^{-1}$.

\section{CHEMICAL EROSION OF the a-C:H LAYER}

First, an in situ experiment was performed with a $63.5 \mathrm{~nm}$ thick $\mathrm{a}-{ }^{13} \mathrm{C}: \mathrm{H}$ layer at elevated temperature exposed to deuterium atoms. The sample was analysed by $1.56 \mathrm{MeV}$ protons (PES) before exposing it to the $\mathrm{D}$ atom beam and the measured spectrum is presented in Fig. 3a. A sharp peak corresponding to ${ }^{13} \mathrm{C}$ is observed on top of a broad, dominant RBS signal corresponding to the bulk Si substrate. The crosssection for elastic proton scattering by ${ }^{12} \mathrm{C}\left({ }^{12} \mathrm{C}(\mathrm{p}, \mathrm{p}){ }^{12} \mathrm{C}\right)$ at $1.56 \mathrm{MeV}$ impact energy is 7.4 times higher $^{21,22}$ than the Rutherford cross-section and the carbon signal can be well separated from the Si background and, consequently, for ${ }^{13} \mathrm{C}$ we can assume that the cross-section is also increased compared to Rutherford scattering. The $\mathrm{CS}$ for ${ }^{13} \mathrm{C}(\mathrm{p}, \mathrm{p}){ }^{13} \mathrm{C}$ was measured by Milne ${ }^{23}$ at $\vartheta=158.3^{\circ}$ in the $0.3-1.6 \mathrm{MeV}$ energy range and by Kashy et al. ${ }^{24}$ at $\vartheta=163.8^{\circ}$ in the $2.6-5.0 \mathrm{MeV}$ energy range. Because we know the layer thickness from ellipsometry $(63.5 \mathrm{~nm})$ and the ${ }^{13} \mathrm{C}$ layer density $\left(9 \times 10^{22} \mathrm{C} \text { at.cm }{ }^{-3}\right)^{9,3}$ we can calculate the ${ }^{13} \mathrm{C}$ areal density to be $5.7 \times 10^{17}{ }^{13} \mathrm{C}$ at. $/ \mathrm{cm}^{2}$ and, with this value known, we can determine the cross-section for our experimental conditions. Assuming that the energy dependence is the same as for the ${ }^{12} \mathrm{C}(\mathrm{p}, \mathrm{p}){ }^{12} \mathrm{C}$ cross-section, ${ }^{21,22}$ a good agreement between the measured and the simulated spectrum calculated by SIMNRA was obtained if the cross-section for ${ }^{13} \mathrm{C}(\mathrm{p}, \mathrm{p}){ }^{13} \mathrm{C}$ was taken to be half the $\mathrm{CS}$ for ${ }^{12} \mathrm{C}(\mathrm{p}, \mathrm{p}){ }^{12} \mathrm{C}$. The cross-section for ${ }^{13} \mathrm{C}(\mathrm{p}, \mathrm{p}){ }^{13} \mathrm{C}$ at $1.56 \mathrm{MeV}$ proton energy at $\vartheta=165^{\circ}$ is presently assumed to be $85 \times 10^{-27} \mathrm{~cm}^{2} / \mathrm{sr}$, which is in reasonable agreement with CS at $\vartheta=158.3^{\circ}\left(100 \times 10^{-27} \mathrm{~cm}^{2} / \mathrm{sr}\right)$ measured by Milne. ${ }^{23}$ The simulated spectrum is also in good agreement with the experimental spectrum with respect to the Si edge being located at $1300 \mathrm{keV}$. This means that the stopping 
of the proton beam in the a- ${ }^{13} \mathrm{C}: \mathrm{H}$ top layer, leading to the shift of the Si edge, is in agreement with the determined carbon density.

After the initial measurement with the proton beam, the ${ }^{7} \mathrm{Li}$ beam was used to characterize the initial state of the sample in the following manner: Employing the Li ion beam we simultaneously obtained the RBS signal and the information on the $\mathrm{H}$ concentration in the layer by the ERDA ion beam method. In the Li-RBS spectrum (Fig. 3b) the carbon signal cannot be separated from the broad RBS signal corresponding to the Si substrate due to its small CS. However, in the simulation of the Li-RBS spectrum the a-C:H layer on top of the Si substrate has to be included into the target layer definition to reproduce the correct position of the Si edge, as just discussed for the proton beam, and with the energy calibration for RBS the agreement between the experimental and the simulated Si edge was very good. The $\mathrm{H}$ concentration of the still unexposed hard $\mathrm{a}-{ }^{13} \mathrm{C}: \mathrm{H}$ layer was determined by ERDA to be $33 \pm 0.5$ at. \% (H:C ratio $\sim 1: 2$ ), which is in good agreement with the literature.,

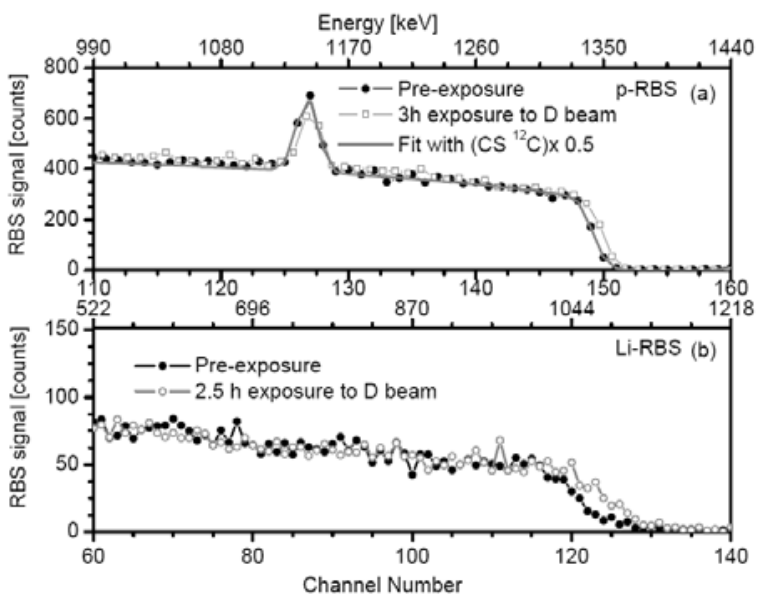

Figure 3. (a) RBS spectra measured by the $1.56 \mathrm{MeV}$ proton beam before and after the exposure to the $\mathrm{D}$ beam at $580 \mathrm{~K}$ sample temperature. Carbon ${ }^{13} \mathrm{C}$ is visible as a peak on top of the step-like signal from the bulk Si substrate. A simulated spectrum, where the ${ }^{13} \mathrm{C}$ peak was fitted by using the cross section for ${ }^{12} \mathrm{C}(\mathrm{p}, \mathrm{p}){ }^{12} \mathrm{C}$ divided by two, is shown as a solid line. The shift of the Si edge accompanied by a decrease of the ${ }^{13} \mathrm{C}$ peak is due to the erosion of the a- ${ }^{13} \mathrm{C}: \mathrm{H}$ layer. (b) RBS spectra measured by the Li beam before and after the exposure to D. The RBS carbon signal cannot be separated from the Si bulk signal but the shift at the Si edge due to the erosion of a${ }^{13} \mathrm{C}: \mathrm{H}$ layer is clearly visible.

After characterizing the sample by the proton beam the sample was heated to $580 \mathrm{~K}$, probed by the $\mathrm{Li}$ ion beam and then exposed to D atoms. At the end of the exposure the layer was again probed by the proton beam. No change in the layer thickness was observed due to the heating, in agreement with the study by Salançon et $\mathrm{al}^{25}$ which found that the thermal decomposition of dense a-C:H layers due to heating starts only above $650 \mathrm{~K}$.

All experimental parameters (HABS driving pressure, background pressure, sample and HABS temperature) were recorded during the exposure. The average HABS driving pressure was 0.19 mbar and the sample was exposed to the $\mathrm{D}$ beam for 215 min while ERDA and RBS spectra were recorded in regular intervals during the exposure. During the erosion the Si edge position in the RBS spectrum shifts towards higher energies as the layer on top of the Si substrate becomes thinner; namely, the Li ions are losing less energy in the thinner a-C:H layer. This RBS edge shift is shown in Fig. $3 \mathrm{~b}$ for the case of the Li ion beam and in Fig. 3a for the case of the proton beam. For both cases, spectra before and $\operatorname{after}(2.5 \mathrm{~h}$ for $\mathrm{Li}$ ions and $3 \mathrm{~h}$ for $\mathrm{p}$ ) exposure to the $\mathrm{D}$ beam are shown and, as in the above case, the shift of the Si edge can be clearly seen in both cases, whereas in the case of the proton beam the ${ }^{13} \mathrm{C}$ peak also becomes smaller.

The $\mathrm{H}, \mathrm{D}$ and ${ }^{13} \mathrm{C}$ areal densities and the $(\mathrm{H}+\mathrm{D}) / \mathrm{C}$ ratio versus time, as obtained from the measured ERDA and RBS spectra, are shown in Fig. 4. Time zero denotes the start of the exposure to D atoms and the first 30 minutes of the $\mathrm{D}$ exposure are shown in Fig $4 \mathrm{~b}$ on an extended scale. The ${ }^{13} \mathrm{C}$ areal density was obtained from fitting the Li-RBS spectra by SIMNRA, i.e. from fitting the Si edge by inserting the $\mathrm{H}$ and $\mathrm{D}$ areal densities obtained by ERDA, and varying the $\mathrm{C}$ areal density until the best agreement is obtained. At the end of exposure the Li probing beam was replaced by the proton beam for the final determination of the ${ }^{13} \mathrm{C}$ areal density; the switching from the Li beam to the proton beam is marked in Fig. $4 \mathrm{a}$ by a vertical line at about $170 \mathrm{~min}$. The $\mathrm{D}$ exposure continued until $215 \mathrm{~min}$. It can be seen that right after the start of the exposure the D density increases and stabilizes whereas the $\mathrm{H}$ and $\mathrm{C}$ densities decrease with time.

From the estimate of the $\mathrm{C}$ areal density and assuming the initial $\mathrm{C}$ volume density we can determine the layer thickness. The final thickness determined in this way can be compared to the thickness measured by ellipsometry, as shown in Fig. 2. The estimated layer thickness from the RBS measurement is about $37 \mathrm{~nm}$, determined from the final $\mathrm{C}$ areal density $\left(330 \times 10^{15} \mathrm{~cm}^{-2}\right)$. From the ellipsometry measurement the average final layer thickness in the area where the beam was hitting is $45 \pm 1 \mathrm{~nm}$, assuming a $1 \mathrm{~nm}$ thick native oxide interface between the substrate and the film. Because we do not know the exact thickness of this interface the agreement is acceptable.

The real-time observation of the hydrogen and carbon areal density variation gives insight into the processes during the erosion of a-C:H layers. At the beginning of the exposure to deuterium atoms the film starts to incorporate the 
incoming $\mathrm{D}$ and the $\mathrm{D}$ areal density starts to increase, as is seen in Fig. 4b. This increase occurs in approximately $4.5 \mathrm{~min}$, corresponding to a D fluence of $2.2 \times 10^{17} \mathrm{D}$ at. $\mathrm{cm}^{-2}$ (average D flux density $8.4 \times 10^{14}$ at.cm $\mathrm{cm}^{-2}$ ). After the initial increase up to $(7.3 \pm 1.3) \times 10^{15}$ at. $^{-2}$ the deuterium areal density slightly decreases and stabilizes at about $(5.5 \pm 1) \times 10^{15}$ at. $\mathrm{cm}^{-2}$. In contrast to this clear uptake of $\mathrm{D}$ the change in $\mathrm{H}$ is harder to detect because of the large initial hydrogen density in the layer but, by comparing the average $\mathrm{H}$ areal density obtained from four spectra before the start of exposure to the $\mathrm{D}$ atom beam and from five spectra $4.5 \mathrm{~min}$ after the start of exposure (Fig $4 \mathrm{~b}$ ), one obtains a total $\mathrm{H}$ areal density decrease of $\sim(10 \pm 5) \times 10^{15}$ at. $\mathrm{cm}^{-2}$. There is a noticeable initial increase in the $\mathrm{H}$ areal density immediately after the start of exposure to $\mathrm{D}$ atom beam which could be induced by an initial transient phase of enhanced adsorption of hydrocarbons from the background gas, due to the $\mathrm{D}$ interaction with the film, which is not yet counterbalanced by carbon erosion. However, in that case the carbon areal density should also increase, which is not observed. This increase of $\mathrm{H}$ areal density could possibly be an artifact since the accumulated dose of the spectra recorded from 2 min prior to 14 min after the start of exposure is 2.5 times smaller than for the other spectra. Approximately at the same time the D areal density stabilizes, the $\mathrm{H}$ areal density starts to steadily decrease. The carbon areal density slowly drops in the first 90 min whereupon the carbon erosion rate increases, reaching a roughly constant rate after about $150 \mathrm{~min}$.

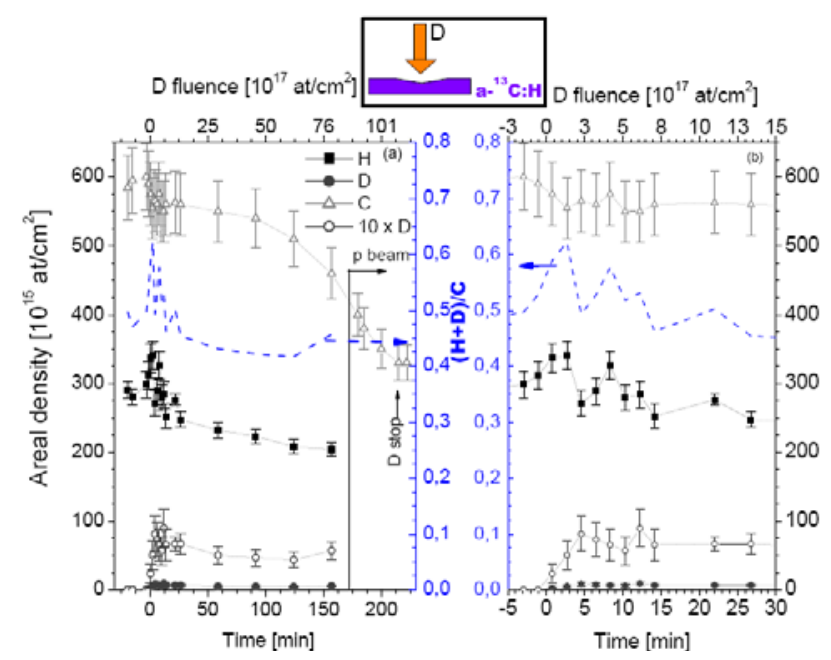

Figure 4. (a) Evolution of $\mathrm{H}, \mathrm{D}$ and $\mathrm{C}$ areal densities during the erosion experiment at $580 \mathrm{~K}$ sample temperature. Each data point for the $\mathrm{H}$ and $\mathrm{D}$ areal density was obtained from an ERDA spectrum recorded with the $\mathrm{Li}$ beam. The $\mathrm{C}$ areal density was determined from the shift of the $\mathrm{Si}$ edge. The ratio $(\mathrm{H}+\mathrm{D}) / \mathrm{C}$ is shown as a dashed line. (b) The initial part of the data from (a) displayed on a shorter time scale for the first 30 minutes.
The erosion process can be explained with the help of a schematic illustration of the processes occurring on the surface, as seen in Fig. 5.24 in Ref. 26, p. 308. When the surface is exposed to H/D atoms two processes can occur: First, hydrogen atoms can be added to the surface, resulting in it becoming more $\mathrm{sp}^{3}$ hybridized and transforming the layer from hard to soft a-C:H. ${ }^{2,27}$ Hard a-C:H layers consist approximately of $70 \% \mathrm{sp}^{3}$ bonds and $30 \% \mathrm{sp}^{2}$ bonds. ${ }^{27}$ Additionally, impinging atoms can abstract bonded hydrogen atoms, thereby creating dangling bonds. At sample temperatures above $400 \mathrm{~K}$, this activated surface state can relax by the emission of a $\mathrm{CH}_{\mathrm{x}}$ radical in the direct neighbourhood of the dangling bond and with the simultaneous formation of an $\mathrm{sp}^{2}$ hybridized carbon atom. This $\mathrm{sp}^{2}$ bond can then again be transformed by hydrogenation into a $\mathrm{sp}^{3}$ bond, and so the erosion circle continues.

A similar study of the erosion of hard a-C:H layers by a $\mathrm{D}$ atom beam has been performed recently by Oehrlein et al. ${ }^{28}$ at similar atom fluxes but lower substrate temperature $(330 \mathrm{~K})$. Analysis was done in their case by in situ ellipsometry and ex situ by NRA and, comparing their results to ours, a similar value was obtained for the uptake of D. They have attributed the initial increase of the $\mathrm{D}$ areal density to isotopic exchange (up to $5 \times 10^{15}$ at. $\mathrm{cm}^{-2}$ ) with further D uptake of $2.5 \times 10^{15}$ at. $\mathrm{cm}^{-2}$ attributed to the conversion of the hard a$\mathrm{C}: \mathrm{H}$ film into a soft layer. The soft layer formation continues for another $160 \mathrm{~min}$ in their case until steady state erosion starts to proceed.

In our case we also observe isotopic exchange, namely an increase of $\mathrm{D}$ and a decrease of $\mathrm{H}$, where the drop of the $\mathrm{H}$ areal density has a similar value as the increase of the D areal density. Oehrlein et al. ${ }^{28}$ could not separate unambiguously the transformation of the top layer and the onset of erosion. However, we can directly see the erosion by following the $\mathrm{C}$ signal and the transformation by looking at the $\mathrm{H}$ and D signal separately. Beside the fact that in our case the erosion proceeds faster due to higher sample temperature, we observe a clear change in slope of the $\mathrm{C}$ areal density decrease after $90 \mathrm{~min}$. Therefore we attribute the first $90 \mathrm{~min}$ (D fluence $4.6 \times 10^{18}$ at. $\mathrm{cm}^{-2}$ ) to layer transformation into a soft layer which is accompanied by a small amount of erosion and, when the soft layer is formed, the steady state erosion starts. The $\mathrm{D}$ areal density of $(5.5 \pm 1) \times 10^{15}$ at. $\mathrm{cm}^{-2}$ during the steady state erosion phase has the same value as observed by Oehrlein et al. ${ }^{28}$, which is attributed to the initial uptake by isotope exchange. Since the D areal density is more or less constant during the erosion, the $\mathrm{D}$ atoms act only on the top of the surface constantly transforming the a-C:H layer and maintaining the top, highly deuterated soft layer. Additionally, one can also observe that the decrease in $\mathrm{C}$ and $\mathrm{H}$ areal densities are not correlated in the initial phase which could 
indicate that the decrease of $\mathrm{H}$ corresponds mainly to $\mathrm{H}$ abstraction by $\mathrm{D}$ atoms leading to $\mathrm{HD}$ molecule formation, while the $\mathrm{C}$ decrease is mainly due to erosion and the eroded hydrocarbon radicals are mainly $\mathrm{C}_{\mathrm{x}} \mathrm{D}_{\mathrm{y}}$. Only during steady state erosion they should be closely correlated.

\section{CARBON LAYER DEPOSITION}

In addition to the erosion study at $580 \mathrm{~K}$, a-C:H samples were also exposed to hydrogen atoms at room temperature. From the previous erosion experiments and available data ${ }^{8,26,28}$ one would expect very little or no erosion of the sample. Contrary to this expectation we observed, ex situ by ellipsometry, an increase of the layer thickness for exposure at room temperature (RT) and, in some previous experiments, at a few $10 \mathrm{~K}$ above RT. In order to elucidate this observation $\mathrm{a}-{ }^{13} \mathrm{C}: \mathrm{H}$ films were prepared and an in situ study of D atom beam exposure at RT was performed.

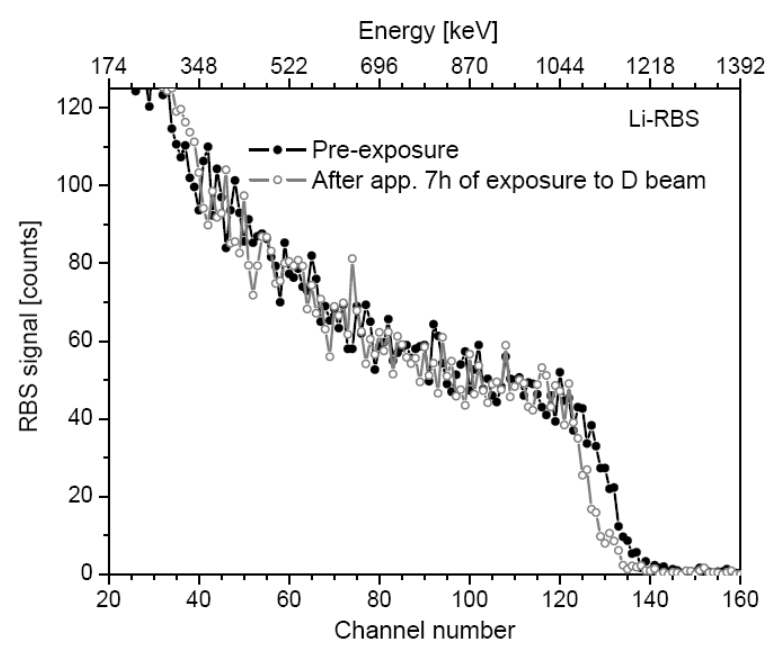

Figure 5. RBS spectra measured by the $\mathrm{Li}$ ion beam before and after the exposure to D at $296 \mathrm{~K}$. The carbon signal is not able to be detected but the shift toward lower energies due to the deposition of $\mathrm{C}: \mathrm{H}$ layer is observed.

A sample with a $20 \mathrm{~nm}$ thick a- ${ }^{13} \mathrm{C}: \mathrm{H}$ layer on a $\mathrm{Si}$ substrate was exposed to a $\mathrm{D}$ beam for $7 \mathrm{~h} 13 \mathrm{~min}$. The sample temperature during this experiment was $296 \mathrm{~K}$ and the background vacuum pressure was $5 \times 10^{-7}$ mbar. The driving pressure during the exposure was $0.185 \mathrm{mbar}$, increasing the pressure in the vacuum chamber to $1.1 \times 10^{-6}$ mbar. During the exposure Li-ERDA and Li-RBS spectra were recorded at regular intervals. The Li-RBS spectra recorded before the exposure and at the end of exposure are shown in Fig. 5, where it can be seen that the Si edge shifts toward lower energies which is an indication that the layer thickness increases, i.e. an additional layer grows on top of the initial one. After the exposure the sample was also analysed by the pro- ton beam and an RBS spectrum obtained with $1.56 \mathrm{MeV}$ protons is shown in Fig. 6. Two peaks are superimposed on the $\mathrm{Si}$ signal while, in the case of the erosion experiment (Fig. 3a), only a single peak was observed. The observed double peak was fitted with an $\mathrm{a}-{ }^{12} \mathrm{C}: \mathrm{H}$ layer, with $1.2 \times 10^{17} \mathrm{~cm}^{-2}{ }^{12} \mathrm{C}$ areal density, on top of the initial a- ${ }^{13} \mathrm{C}: \mathrm{H}$ layer. For the ${ }^{13} \mathrm{C}$ peak the ${ }^{12} \mathrm{C}(\mathrm{p}, \mathrm{p}){ }^{12} \mathrm{C}$ cross-section divided by two was used for the ${ }^{13} \mathrm{C}(\mathrm{p}, \mathrm{p}){ }^{13} \mathrm{C}$ cross-section, as explained previously. The agreement between the experimental and the simulated spectrum for the carbon peaks and Si edge is very good, confirming the applied cross-section approximation. These measurements clearly show that the increase of the layer thickness is a consequence of an additional ${ }^{12} \mathrm{C}$ layer growing on top of the original a- ${ }^{13} \mathrm{C}: \mathrm{H}$ layer.

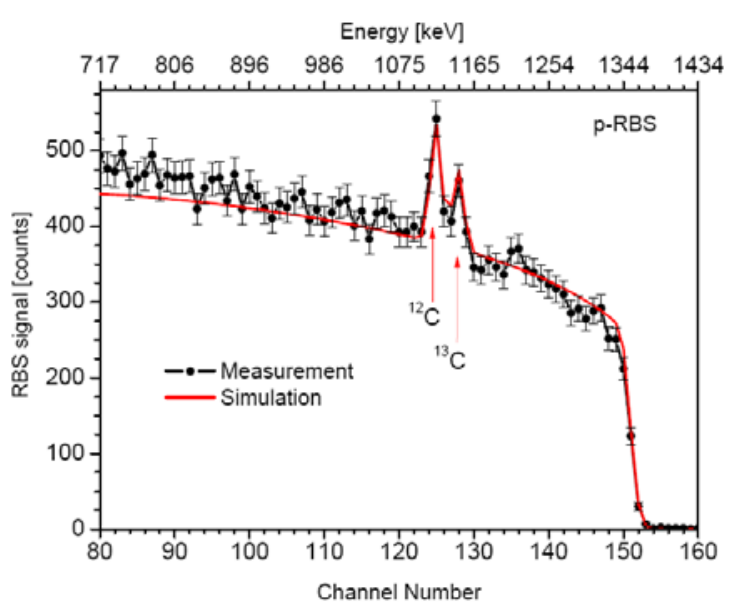

Figure 6. Measured and simulated RBS spectra obtained by a $1.56 \mathrm{MeV}$ proton beam. For the simulated spectrum, an accurate cross section for ${ }^{12} \mathrm{C}(\mathrm{p}, \mathrm{p}){ }^{12} \mathrm{C}$ from Ref. 21 is used for the ${ }^{12} \mathrm{C}$ peak, while an adjusted value $(\times 0.5)$ is used for ${ }^{13} \mathrm{C}$.

The time variation of the $\mathrm{H}$ and $\mathrm{D}$ areal densities obtained from the ERDA spectra together with the ${ }^{12} \mathrm{C}$ areal density are shown in Fig. 7. The ${ }^{12} \mathrm{C}$ areal density was obtained with the above described procedure; fitting the Si edge by adding an additional ${ }^{12} \mathrm{C}$ layer together with the $\mathrm{D}$ and $\mathrm{H}$ areal densities obtained from ERDA. Namely, the shift of the Si edge was fitted by adding a ${ }^{12} \mathrm{C}: \mathrm{D}$ layer on top of the initial $20 \mathrm{~nm}$ thick a- ${ }^{13} \mathrm{C}: \mathrm{H}$ layer. One can observe one interesting phenomenon for this layer growth; namely, during the exposure the $\mathrm{D}$ and $\mathrm{C}$ areal densities are increasing at the same rate $\left(4.5 \times 10^{12}\right.$ at. $\left.\mathrm{cm}^{-2} \mathrm{~s}^{-1}\right)$, whereas the $\mathrm{H}$ areal density growth rate is much slower $\left(1.4 \times 10^{12}\right.$ at. $\left.\mathrm{cm}^{-2} \mathrm{~s}^{-1}\right)$. The deposited layer has a $(\mathrm{D}+\mathrm{H}): \mathrm{C}$ ratio of approximately $1: 1$, which is typical for polymer-like layers. ${ }^{2}$ The $\mathrm{D}:{ }^{12} \mathrm{C}$ ratio is shown in Fig. 7 , where the mean value is 0.9 , clearly showing that the deposited layer contains mainly the $\mathrm{D}$ hydrogen isotope. Since the deposited hydrocarbons, $\mathrm{C}_{\mathrm{x}} \mathrm{H}_{\mathrm{y}}$, originate from the background vacuum, this observation indicates that the iso- 
tope exchange is very effective during layer growth, with $\mathrm{D}$ atoms replacing most of the $\mathrm{H}$ atoms from $\mathrm{C}_{\mathrm{x}} \mathrm{H}_{\mathrm{y}}$ during the deposition.

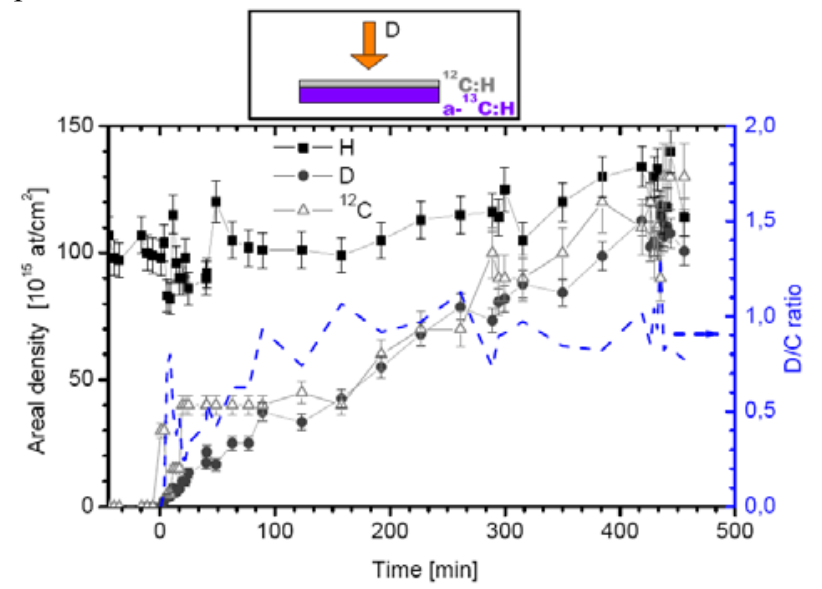

Figure 7. H, D and C areal densities during the exposure at $296 \mathrm{~K}$. Each data point of the $\mathrm{H}$ and $\mathrm{D}$ areal density was obtained from one ERDA spectrum procured by the Li beam. The $\mathrm{C}$ areal density represents the carbon mass 12 that is being deposited on top of the a${ }^{13} \mathrm{C}: \mathrm{H}$ layer and was determined from the shift of the Si edge. The ratio $\mathrm{D} /{ }^{12} \mathrm{C}$ is shown as a dashed line.

After the exposure the sample was analysed by ellipsometry and the lateral thickness profile of the sample is shown in Fig. 8. The deposited thickness profile is seen to be homogeneous with a $29 \mathrm{~nm}$ thick deposited layer on top of the original $\mathrm{a}-{ }^{13} \mathrm{C}: \mathrm{H}$ layer and the obtained film growth rate was $3.9 \mathrm{~nm} / \mathrm{h}$. In the centre of the image an elliptical dip is visible which can be attributed to the probing beam which, we expect, is locally heating the surface and, thus, either reducing deposition leading to increased erosion or modifying the optical properties by releasing hydrogen. The resulting final ${ }^{12} \mathrm{C}$ areal density as obtained from $\mathrm{RBS}$ was $1.2 \times 10^{17} \mathrm{~cm}^{-2}$ and, with this $\mathrm{C}$ areal density and the film thickness obtained from ellipsometry we determine the carbon density to be $(4.4 \pm 0.6) \times 10^{22} \mathrm{~cm}^{-3}$, which is in agreement with the literature value for such polymer-like layers. ${ }^{4}$

As mentioned above we have performed more exposure experiments with a-C:H films at low sample temperatures in the same set-up, wherein for all cases, the deposition was homogeneous over the sample and did not show the flux profile of the incoming beam. Comparing the obtained deposition rates for individual samples, one can conclude that there is a correlation between the background vacuum and the deposition rate; namely, as the vacuum pressure improves, reduced deposition is observed. This supports the assumption that the deposited layer is due to the hydrocarbon impurities in the background vacuum.
We also observed similar deposition of polymer-like carbon layers on tungsten, tantalum and copper when exposed to D or $\mathrm{H}$ beams at low sample temperature ${ }^{29}$. During these exposures the edge signal in the RBS spectrum, corresponding to the analyzed metal, was shifted toward lower energies and, simultaneously, the hydrogen areal density increased without showing any saturation. Similarly the erosion of this carbon contamination could be followed using the RBS when the metal sample was exposed to hydrogen atoms at elevated temperatures $(>470 \mathrm{~K})$ and, therefore, carbon deposition and its removal from metal samples can be quantitatively monitored by the RBS ion beam technique; i.e. by analyzing the shift of the substrate RBS edge assuming no other impurities are incorporated into the layer.

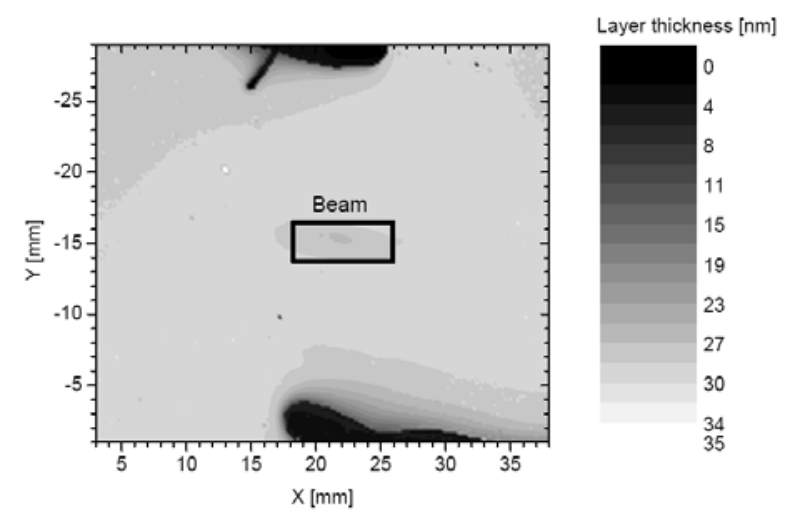

Figure 8. Lateral thickness distribution after the exposure to the D beam at $296 \mathrm{~K}$. The thickness is homogeneous, representing a homogenous deposited layer on top of the initial layer. The reference thickness was provided by masking the sample with holding clamps. The small elliptical crater in the middle is the trace of the probing $\mathrm{MeV}$ ion beam, since ERDA and RBS spectra were recorded during the $\mathrm{D}$ exposure.

Hydrocarbon film growth obtained by exposing a sample to a known flux of methyl radicals $\left(\mathrm{CH}_{3}\right)$ and atomic hydrogen has been extensively studied in the past ${ }^{4}$ where it was shown that the $\mathrm{H}$ atoms increase the methyl radical sticking coefficient by two orders of magnitude. This is because hydrogen atoms can abstract surface-bonded hydrogen and leave the surface as $\mathrm{H}_{2}$ molecules, thereby creating dangling bonds on which the radicals adsorb very efficiently. The deposited layer in such beam experiments shows a $\mathrm{H}: \mathrm{C}$ ratio $\approx 1$ and a similar value was found for the deposited layer in the present study. A model was developed for these previous results, describing the hydrogen atom and radical addition and recombination with an adsorbed hydrogen atom and the erosion of radicals due to neighbouring dangling bond formation, which is described in more detail in several studies $^{4,30,31}$. The model described the experimental results very well; e.g. deposition rate, dynamic behaviour of the deposi- 
tion; and providing also the cross-section values for individual processes. The measurements and also the model showed that at high hydrogen atom fluxes compared to the hydrocarbon radical flux, the rate limiting step is determined by the supply of the carbon-carrying species and, at that stage, the growth rate becomes independent of the hydrogen flux.

The deposition in our experiment takes place only if the deuterium (hydrogen) atoms are present and if the sample temperature is not higher than about $350 \mathrm{~K}$. Although the D flux density varies by a factor of five across the sample $\left(2 \times 10^{14} \mathrm{~cm}^{-2} \mathrm{~s}^{-1}\right.$ at the sample edge and $1 \times 10^{15} \mathrm{~cm}^{-2} \mathrm{~s}^{-1}$ in the centre), the deposited layer does not reflect the beam profile, but instead, the thickness is homogenous across the sample. If we assume that similar processes to those observed for the sticking of methyl radicals ${ }^{30,31}$ lead to the cross-linking of adsorbed long-chain hydrocarbon molecules, we can apply this model to explain the observed deposition of hydrocarbon films in our experiment. According to the model the deposition rate becomes weakly dependent on the hydrogen atom flux density at high hydrogen atom to hydrocarbon flux ratios (factor of 5, Ref. 30) which could also explain the homogeneous deposition observed in the present experiment. However, applying the model ${ }^{31}$ to our D flux density, the maximum carbon deposition rate should be of the order of $10^{11} \mathrm{~cm}^{-2} \mathrm{~s}^{-1}$ or lower, which is much smaller than the rate obtained in the our experiment $\left(4.5 \times 10^{12}\right.$ at. $\left.\mathrm{cm}^{-2} \mathrm{~s}^{-1}\right)$. This difference in deposition rates can be explained if it is assumed that heavier hydrocarbons are depositing on the surface in our experiments. From the model one can also see that the rate changes very fast in a very narrow carbon flux density range where deposition turns into erosion showing that, obviously, the range for the transition from deposition to erosion is very narrow.

The question now remaining is what is the source of the hydrocarbon radicals? They can be produced on all surfaces in the vacuum chamber if atomic hydrogen erodes contamination at these surfaces but, since the walls are at RT, the expected erosion should be small. A certain fraction of radicals could also be formed by dissociation from the hot tungsten capillary of the HABS, but this contribution should also be small. On the other hand, stable hydrocarbons from the background vacuum can impinge on the sample surface and physisorb and we assume that the hydrogen atoms impinging on these physisorbed hydrocarbon molecules lead to permanent film deposition by cross-linking. ${ }^{30}$ It was shown that hydrogen atoms transform ethylene, acetylene and ethane molecules physisorbed on Ni surfaces into a stable ethylidyne $\left(\mathrm{CCH}_{3}\right)$ species which were adsorbed on the surface. ${ }^{7}$ In conclusion, we assume that the layer growth is due to physisorption of long-chain hydrocarbons and cross-linking due to interaction with atomic $\mathrm{H}$ (D) and the net deposition rate for this process depends strongly on the partial pressure of hydrocarbons in the vacuum chamber and the substrate temperature determined by erosion by atomic hydrogen.

\section{CONCLUSIONS}

We have studied erosion and deposition of C:H layers exposed to the D atom beam by in situ RBS and ERDA ion beam methods. We observed for the first time the time evolution of the deuterium uptake that occurs during the erosion process at elevated surface temperature $(580 \mathrm{~K})$ and in addition, we could monitor the variation of the hydrogen/deuterium areal densities during the transformation from a hard to soft layer and the onset of erosion. The experiments with a- ${ }^{13} \mathrm{C}: \mathrm{H}$ enabled us to reveal the origin of the observed layer growth at about $300 \mathrm{~K}$ where it was shown that there is actually an additional ${ }^{12} \mathrm{C}: \mathrm{D}(\mathrm{H})$ layer growing at the surface when atomic deuterium (hydrogen) is impinging at the surface. With these measurements we have obtained insight into how the layer is being deposited, which we propose to be by the incorporation of carbon impurity molecules from the background vacuum. Deuterium (hydrogen) atoms and low surface temperatures are needed for this deposition to take place. On the other hand, such a deposited layer can be removed from the surface by hydrogen atoms at elevated temperatures.

The shift of the Si edge of the RBS spectrum was used to determine the carbon content on the substrate which is possible under the assumption that carbon and hydrogen are the dominant constituents of the deposited layer. The method proved to be useful also for other heavier substrates where carbon determination is even more difficult. The error of the estimated carbon layer thickness is from $10 \%$ to $30 \%$ due to the variation of the stopping power in different $\mathrm{C}: \mathrm{H}$ layers (soft/hard), ${ }^{13}$ but still the method is very useful for monitoring carbon contamination on the surface during the experiment.

Observed hydrocarbon deposition at low surface temperatures is important for any study where hydrogen atoms are present for it may play an important role in hydrogen retention in future fusion reactors in areas hidden from the plasma where RT surfaces are exposed to hydrogen atoms and are, therefore, vulnerable to deposition of hydrogen rich layers.

The cross-section for ${ }^{7} \mathrm{Li}$ on $\mathrm{D}$ at the $4.3 \mathrm{MeV}$ beam energy and $\varphi=30^{\circ}$ recoil angle was also determined to be $(235 \pm 16) \times 10^{-27} \mathrm{~cm}^{2} / \mathrm{sr}$, which is $3.0 \pm 0.2$ times higher than the Rutherford elastic cross-section $\left(79 \times 10^{-27} \mathrm{~cm}^{2} / \mathrm{sr}\right)$. From the measurements with the proton beam at $1.56 \mathrm{MeV}$ we have also obtained an estimate for the ${ }^{13} \mathrm{C}(\mathrm{p}, \mathrm{p}){ }^{13} \mathrm{C}$ cross section at a $\vartheta=165^{\circ}$ scattering angle of $85 \times 10^{-27} \mathrm{~cm}^{2} / \mathrm{sr}$. The SIMNRA simulation agrees with the measured spectra very 
well for both ${ }^{13} \mathrm{C}: \mathrm{H}$ layer thicknesses used in the experiment showing the consistency of the cross section estimate.

\section{ACKNOWLEDGMENTS}

The authors acknowledge the financial support by the Slovenian Research Agency and by Association Euratom-MHEST (Slovenian Fusion Association). The content of the publication is the sole responsibility of its authors and it does not necessarily represent the views of the Commission or its services.

${ }^{1}$ J. Roth, E. Tsitrone, A. Loarte, Th. Loarer, G. Counsel, R. Neu, V. Philips, S. Brezinsek, M. Lehnen, P. Coad, Ch. Grisolia, K. Schmidt, K. Krieger, A. Kallenbach, B. Lipschultz, R. Doerner, R. Causey, V. Alimov, W. Shu, O. Ogorodnikova, A. Kirschner, G. Federichi and A. Kukushkin, J. Nucl. Mater. 390-391, (2009) 1.

${ }^{2}$ W. Jacob, Thin Solid Films 326, 1 (1998).

${ }^{3}$ T. Schwarz-Selinger, A. von Keudell and W. Jacob, J. Appl.Phys. 86, 3988 (1999).

${ }^{4}$ A. von Keudell and W. Jacob, Prog. Surf. Sci. 76, 21 (2004).

${ }^{5}$ H. Umemoto, Chem. Vapour Dep. 16, 275 (2010).

${ }^{6}$ W. Jacob, C. Hopf, A.von Keudell, M. Meier and T. Schwarz-Selinger, Rev. Sci. Instr. 74, 5123 (2003).

${ }^{7}$ T. Bürgi, T.R. Trautman, M. Gostein, D.L. Lahr, K.L. Haug and S.T. Ceyer, Surf. Sci. 501, 49 (2002).

${ }^{8}$ M. Schlüter, C. Hopf, T. Schwarz-Selinger, A. von Keudell, W. Jacob, J. Nuclear Material 376, 33 (2008).

${ }^{9}$ T. Schwarz-Selinger, A. von Keudell and W. Jacob, J. Vac. Sci. and Technol. A 18, 995 (2000).

${ }^{10}$ M.N.R. Ashfold, P.W. May, J.R. Petherbridge, K.N. Rosser, J.A. Smith, Y.A. Mankelevich and N.V. Suetin, Phys. Chem. Chem. Phys 3, 3471 (2001).

${ }^{11}$ J.E. Butler, Y.A. Mankelevich, A. Cheesman, J. Mia and M. N.R. Ashfold, J. Phys.: Condens. Matter 21, 364201 (2009).

${ }^{12}$ S. Markelj, I. Čadež, P. Pelicon, Z. Rupnik, Nucl. Instrum. and Meth. B 259, 989 (2007).

${ }^{13}$ D. Boutard, W. Möller and B. M. Scherzer, Phys. Review B 38, 2988 (1988).

${ }^{14}$ M.El. Bouanani, P. Pelicon, A. Razpet, I. Čadež, M. Budnar, J. Simčič and S. Markelj, Nucl. Instrum. Methods B 243, 392 (2006).

${ }^{15}$ M. Mayer, SIMNRA User's Guide, Report IPP 9/113, MaxPlanck-Instutut für Plasmaphysik, Garching, Germany, 1997 and http://www.rzg.mpg.de/ mam/ .

${ }^{16}$ P. Pelicon, A. Razpet, S. Markelj, I. Čadež and M. Budnar, Nucl. Instrum. Methods B 227, (2005) 591.

${ }^{17}$ Z. Siketić, I. Bogdanovič Radovič, H. Muto and M. Jakšič, Nucl. Instrum. Methods B 229, 180 (2005).
${ }^{18}$ V. Kh. Alimov, M. Mayer, J. Roth, Nucl. Instrum. Meth. B 234, 169 (2005)

${ }^{19}$ P. Pelicon, P. Vavpetič, N. Grlj, I. Čadež, S. Markelj, S. Brezinsek, A. Kreter, T. Dittmar, E. Tsitrone, B. Pegouille, M. Rubel and T. Schwarz-Selinger, Nucl. Instrum. Methods B 269, 2317 (2011).

${ }^{20}$ K.G. Tschersich, J.P. Fleischhauer and H. Schuler, J.Appl.Phys. 104, 034908 (2008).

${ }^{21}$ S. Mazzoni, M. Chiari, L. Giuntini, P. A. Mandò, N. Taccetti, Nucl. Instr. Meth B 136-138, 86 (1998).

${ }^{22}$ A.F. Gurbich, Nucl. Instr. Meth B 136-138, 60 (1998).

${ }^{23}$ E.A. Milne, Phys. Rev. 93, 762 (1954).

${ }^{24}$ E. Kashy, R.R. Perry, R.L. Steele and J.R. Risser, Phys. Rev. 122, 884 (1961).

${ }^{25}$ E. Slançon, T. Dürbeck, T. Schwarz-Selinger, F. Genoese and W. Jacob, J. Nucl. Mater. 376, 160 (2008).

${ }^{26}$ J. Küppers, Surf. Sci. Rep. 22, 249 (1995).

${ }^{27}$ A. von Keudell, T. Schwarz-Selinger, M. Meier and W. Jacob, Appl.Phys. Lett. 76, 676 (2000).

${ }^{28}$ G.S. Oehrlein, T. Schwarz-Selinger, K. Schmid, M. Schüter and W. Jacob, J. App. Phys. 108, 043307 (2010).

${ }^{29}$ I. Čadež, S. Markelj, P. Pelicon and Z. Siketić, Deposition and Erosion of Polymer-like Hydrocarbon Layer by Hydrogen Atoms, 13th PFMC Workshop, Rosenheim, Germany, 10 - 13 May 2011, P02A.

${ }^{30}$ M. Meier and A. von Keudell, J. Appl. Phys. 90, 3585 (2001).

${ }^{31}$ M. Meier, R. Preuss and V. Dose, New J. of Phys. 5, 133.1 (2003). 